
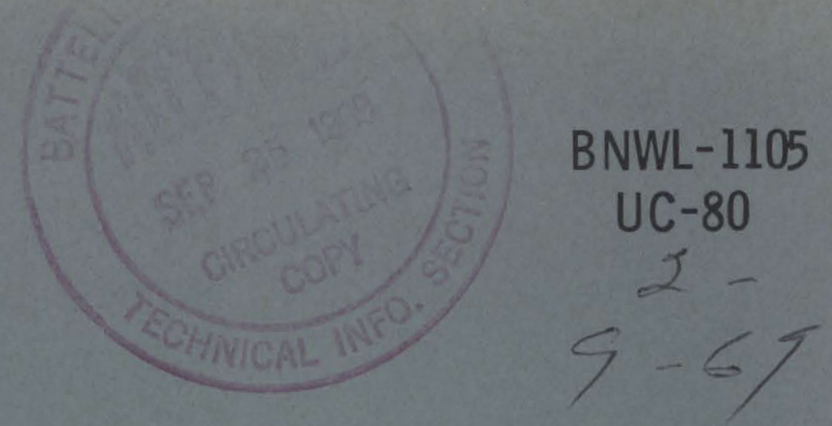

\title{
EFFECT OF STRAIN RATE \\ ON MECHANICAL PROPERTIES \\ OF AUSTENITIC STAINLESS STEELS
}

September 1969

\section{AEC RESEARCH \& DEVELOPMENT REPORT}

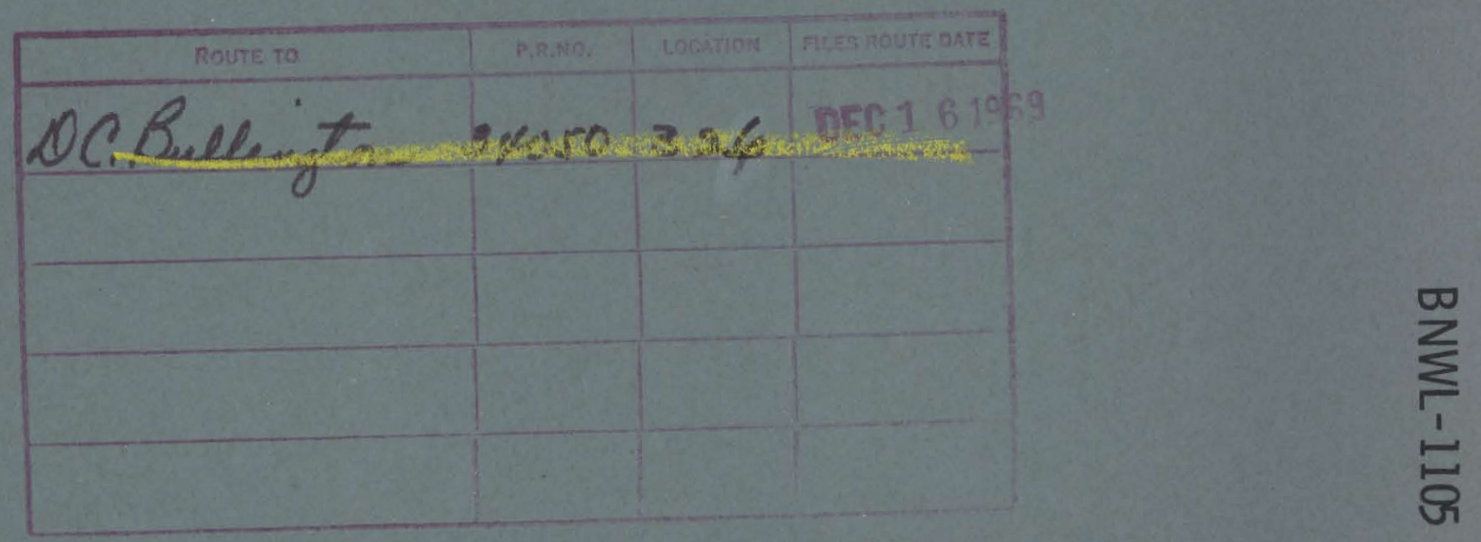

B A T TELLE B NORTHWEST BATTELLE MEMORIAL INSTITUTE DACIFIC NORTHWEST LABORATORIES BATTELLE BOULEVARD, P. O. BOX 999, RICHLAND, WASHINGTON 99352 


\section{LEGAL NOTICE}

This report was prepared as an account of Government sponsored work. Neither the United States, nor the Commission, nor any person acting on behalf of the Commission:

A. Makes any warranty or representation, expressed or implied, with respect to the accuracy, completeness, or usefulness of the information contained in this report, or that the use of any information, apparatus, method, or process disclosed in this report may not infringe privately owned rights; or

B. Assumes any liabilities with respect to the use of, or for damages resulting from the use of any information, apparatus, method, or process disclosed in this report.

As used in the above, "person acting on behalf of the Commission" includes any employee or contractor of the Commission, or employee of such contractor, to the extent that such employee or contractor of the Commission, or employee of such contractor prepares, disseminates, or provides access to, any information pursuant to his employment or contract with the Commission, or his employment with such contractor.

\section{PACIFIC NORTHWEST LABORATORY}

RICHLAND, WASHINGTON

operated by

BATTELLE MEMORIAL INSTITUTE

for the

UNITED STATES ATOMIC ENERGY COMMISSION UNDER CONTRACT AT(45-1)-1830 


\section{EFFECT OF STRAIN RATE ON MECHANICAL PROPERTIES OF AUSTENITIC STAINLESS STEELS \\ By}

R. G. Hoagland

Fuels and Materials Department Chemistry and Metallurgy Division

Issued By

FFTF Engineering Department

September 1969

BATTELLE MEMORIAL INSTITUTE

PACIFIC NORTHWEST LABORATORIES

RICHLAND, WASHINGTON 99352 
BNWL - 1105

Printed in the United States of America Available from

Clearinghouse for Federal Scientific and Technical Information National Bureau of Standards, U.S. Department of Commerce Springfield, Virginia 22151

Price: Printed Copy $\$ 3.00$; Microfiche $\$ 0.65$ 


\section{EFFECT OF STRAIN RATE ON MECHANICAL PROPERTIES OF AUSTENITIC STAINLESS STEELS \\ R. G. Hoagland}

\section{ABSTRACT}

A literature survey of high strain rate effects on the mechanical properties of austenitic stainless steels applicable to fast reactor technology showed little information available. Two general tentative observations were that (1) the flow stress of austenitic stainless steels is more strain rate sensitive above $1000^{\circ} \mathrm{F}$ than below, and (2) ductility parameters are reduced at low temperatures by increasing the strain rate while, at high temperature, the opposite might be true. 
BNWL- 1105

\section{CONTENTS}

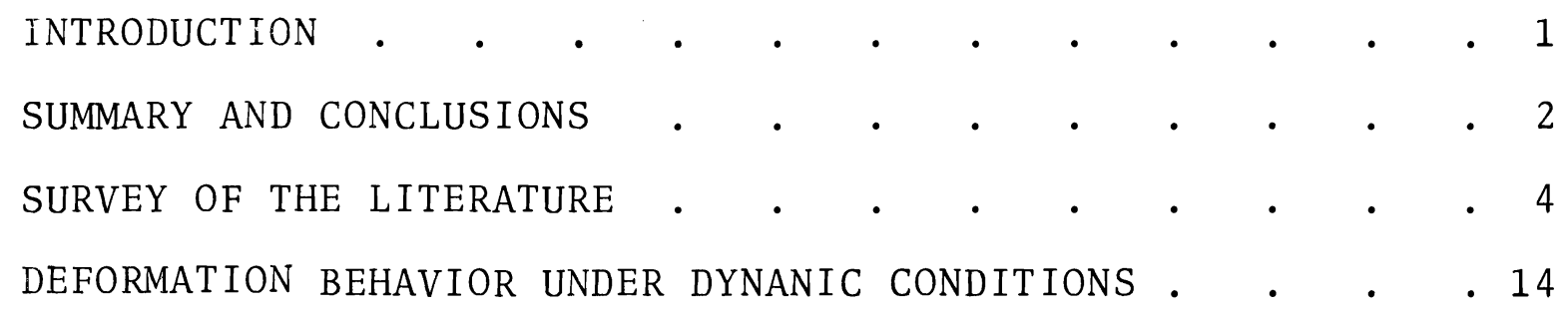




\section{FIGURES}

1 Schematic Interpretation of Rate Sensitive Nature of Stainless Steel Flow Stress

2 Effect of Stress on Strain Rate at Constant Strain for Stainless Steel, Showing Sampling of Experimental Record

3 Ductility of AISI 303 SS as a Function of Strain Rate and Test Temperature

4 Ductility of AISI 310 SS as a Function of Strain Rate and Test Temperature

5 Temperature Effect After 1800-sec Hold Time on $0.2 \%$ Offset Yield and Ultimate Tensile Strength of FullHard 301 SS Sheet at Different Strain Rates (Specimens heated to test temperature in $10 \mathrm{sec}$ )

6 Temperature Effect After 1800-sec Hold Time on Percent Elongation and Modulus of Elasticity of Full-Hard 301 SS Sheet at Different Strain Rates (Specimens heated to test temperatures within $10 \mathrm{sec}$ )

7 Stress-Strain Results for Type 304 SS at Room Temperature

8 Effect of Strain Rate on Yield and U1timate Tensile Strength of Cold Worked 304 SS

9 Effect of Strain Rate on Ductility of Cold Worked 304 SS

10 Schematic of Cylinderical Rod Subjected to Rapid Elongation 


\title{
EFFECT OF STRAIN RATE ON MECHANICAL PROPERTIES \\ OF AUSTENITIC STAINLESS STEELS
}

\author{
R. G. Hoagland
}

\section{INTRODUCTION}

Results of a survey seeking information on the strain rate sensitive behavior of austenitic stainless steels applicable to fast reactor technology are reported herein. The search for this information was made with two problem areas particularly in mind. These problem areas concern the behavior of the large containment vessel and top cover during impact from within, and the behavior of core structure under conditions of thermal pulse and/or rapid loading. To assess structural behavior under such conditions for the purpose of evaluating potential design deficiencies, mechanical properties data on austenitic stainless steels are needed in the temperature range of $500{ }^{\circ} \mathrm{F}$ $\left(260^{\circ} \mathrm{C}\right)$ to $1400^{\circ} \mathrm{F}\left(760^{\circ} \mathrm{C}\right)$ at strain rates of approximately $0.01 \mathrm{sec}^{-1}$ to $100 \mathrm{sec}^{-1}$ or possibly higher. The greatest emphasis from the standpoint of FFTF construction is currently placed on the austenitic stainless steels of the 304 and 316 types. An important consideration is the possible deleterious effects on the high strain rate behavior of these materials due to irradiation damage by neutron fluences as high as $5 \times 10^{23} \mathrm{n} / \mathrm{cm}^{2}$.

Two general aspects involved in the response of metals to high velocity deformation are inseparable in evaluating the integrity of a structure under conditions of rapid loading. The first is the influence of strain rate or time on the stressstrain relationship. This effect, well known to metallurgists, is demonstrated by the fact that the results obtained in a simple tension test depend, for most metals, on the speed at which the testing machine is operated. 
BNWL - 1105

The second general aspect of high velocity deformation is the phenomenon of wave propagation. Strain (or stress) waves become significant when the acceleration of an element of volume of the material is of such a magnitude that the inertia forces in the element become comparable to the flow stress forces. A great variety and complexity of propagating strain waves may be developed, depending upon the manner of applying external loads, the size and shape of the piece of metal, and the generalized stress-strain to strain rate relation for the material. In other words, the mechanical behavior of the metal becomes sensitive to its geometry as the straining velocity increases.

This report discusses both aspects of the high strain rate behavior of austenitic stainless steels and, therefore, is separated into two sections. The first section presents the results of a literature survey of material behavior. The second section describes, in greater detail, some of the complexities in data analysis which develop at high strain rates.

\section{SUMMARY AND CONCLUSIONS}

A survey of the literature indicated available data on the effect of strain rate on flow properties of austenitic stainless steel to be relatively limited. Much of the available data were obtained more with the intent to evaluate or demonstrate a test technique than to study a materials behavior. It should be noted that no information on the strain rate sensitivity of austenitic stainless steels irradiated to high fluences $\left(>10^{21} \mathrm{n} / \mathrm{cm}^{2}\right)$ could be found. Furthermore, for the two alloys of particular interest, annealed 304 and $316 \mathrm{SS}$, no data could be found for either the temperature or the strain rate ranges identified for FFTF application.

Consideration was also given to the manner in which nonuniform stresses may develop in a rapidly loaded body. The 
simple example discussed was a uniform rod rigidly fixed at one end, and the other end given an axial velocity.

The essential conclusions obtained in this study can be summarized as follows:

- The flow stress of several annealed stainless steels is more strain rate sensitive above $\mathrm{T}_{\mathrm{m}} / 2\left(1030^{\circ} \mathrm{F}\right)$ than below. This condition may indicate that the rate controlling deformation process changes in the vicinity of $\mathrm{T}_{\mathrm{m}} / 2$. At strain rates above approximately $100 \mathrm{sec}^{-1}$, the bounatary between low and high rate sensitivity appears to shift to a lower temperature. This behavior is schematized in Figure 1 .

- A very limited amount of data indicates that ductility parameters below about $550^{\circ} \mathrm{F}$ are reduced by increasing strain rate, while the opposite is true at higher temperatures. Cold working may promote reduced ductility at both higher temperatures and higher strain rates.

- According to the data of Martin and Weir, obtained at strain rates below $3 \times 10^{-2} \mathrm{sec}^{-1}$, irradiation does not significantly alter these conclusions. It should be recognized that this insensitivity to neutron fluence may not be obeyed at higher strain rates.

- For complex geometries composed of rate sensitive materials, a realistic incorporation of mechanical behavior data into an analysis of the high velocity mechanical behavior of the structure may require difficult numerical calculations and/or an experimental evaluation of subscale model behavior. 
BNWL - 1105

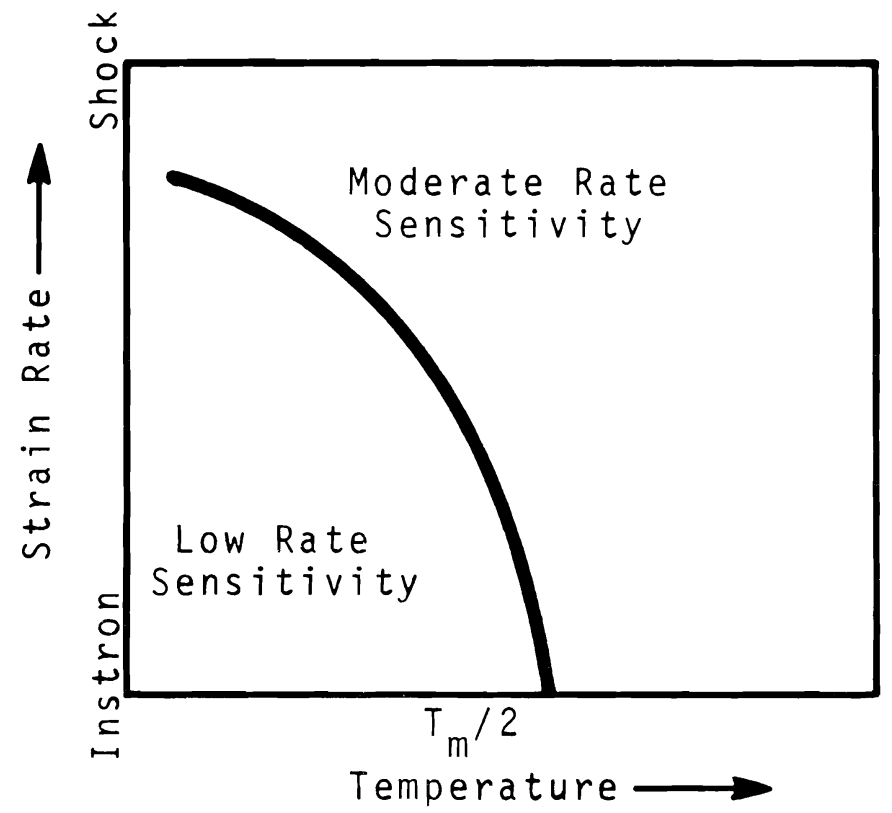

\section{FIGURE 1. Schematic Interpretation of Rate Sensitive Nature of Stainless steel Flow stress}

\section{SURVEY OF THE LITERATURE}

In general, the amount of information concerning the high strain rate behavior of austenitic stainless steels is quite limited. Much of the available data were obtained more with the intent to evaluate or demonstrate a test technique rather than to study a material behavior. In particular, no data on the high strain rate behavior of austenitic steels irradiated in a fast reactor to very high fluence levels could be found. Perhaps the most relevant information currently existing is that obtained by Martin and Weir ${ }^{(1)}$ on annealed 304 and 347 SS. The data, although obtained at relatively low strain rates, did evaluate a strain rate behavior on subsize tensile specimens irradiated at temperatures from $340^{\circ} \mathrm{F}\left(170{ }^{\circ} \mathrm{C}\right)$ to $1300^{\circ} \mathrm{F}$ $\left(704^{\circ} \mathrm{C}\right.$ ) and tested at temperatures from room temperature to $1560^{\circ} \mathrm{F}\left(850^{\circ} \mathrm{C}\right)$. The irradiations were conducted in the ORR to a fluence level of approximately $7 \times 10^{20} \mathrm{n} / \mathrm{cm}^{2}(\mathrm{E}>1 \mathrm{MeV})$, 
and the strain rates were varied from $3.3 \times 10^{-5} \mathrm{sec}^{-1}$ to $3.3 \times 10^{-2} \mathrm{sec}^{-1}$.* The flow properties of 304 ss were observed to be strain rate insensitive** in either the unirradiated or irradiated conditions below a test temperature of about $\mathrm{T}_{\mathrm{m}} / 2$ $\left(1030^{\circ} \mathrm{F}\right)$. Above this temperature and for this range of strain rates, the flow properties become more rate sensitive although neither fluence nor irradiation temperature affect the rate sensitivity. At $1550^{\circ} \mathrm{F}\left(843^{\circ} \mathrm{C}\right)$, the yield strength is unaffected in going from a strain rate of $3.3 \times 10^{-5} \mathrm{sec}$ to $3.3 \times 10^{-2} \mathrm{sec}^{-1}$, while increase in the true ultimate strength by approximately 2.5 indicates a significant dependence of strain hardening on strain rate in this temperature range. At room temperature, Martin and Weir found that the ductility, in terms of uniform elongation, was reduced with increasing strain rate. However, the ductility parameter was insensitive to strain rate at $750^{\circ} \mathrm{F}\left(400^{\circ} \mathrm{C}\right)$ and increased with strain rate at $1550{ }^{\circ} \mathrm{F}\left(843^{\circ} \mathrm{C}\right)$. This latter effect is consistent with the interpretation that, at high temperatures, the fracture mode of stainless steels occurs primarily by grain boundary decohesion. Because formation of critical size grain boundary cracks is believed to be diffusion controlled, the time under stress would control the ductility.

Hauser (2) has measured the room temperature flow stress behavior of annealed Type 304 SS in the strain rate range of from $1 \times 10^{-4} \mathrm{sec}^{-1}$ to $1 \times 10^{3} \mathrm{sec}^{-1}$. Results of these data, shown in Figure 2 indicate a moderate rate sensitivity in the flow stress. The flow stress becomes more rate sensitive above strain rates of about $10 \mathrm{sec}^{-1}$. The data, obtained from a

* For consistency, all strain rates are given in this report in terms of $\mathrm{sec}^{-1}$.

* Strain rate sensitivity as discussed in this report refers to the degree of response of the change in parameter (flow stress, ductility, etc.) due to a change in strain rate. Mathematically, it may be referred to as $\frac{\partial \ln \tau}{\partial I_{n} \varepsilon}$ or $\frac{\partial \ln \tau}{\partial \varepsilon}$. 
BNWL- 1105

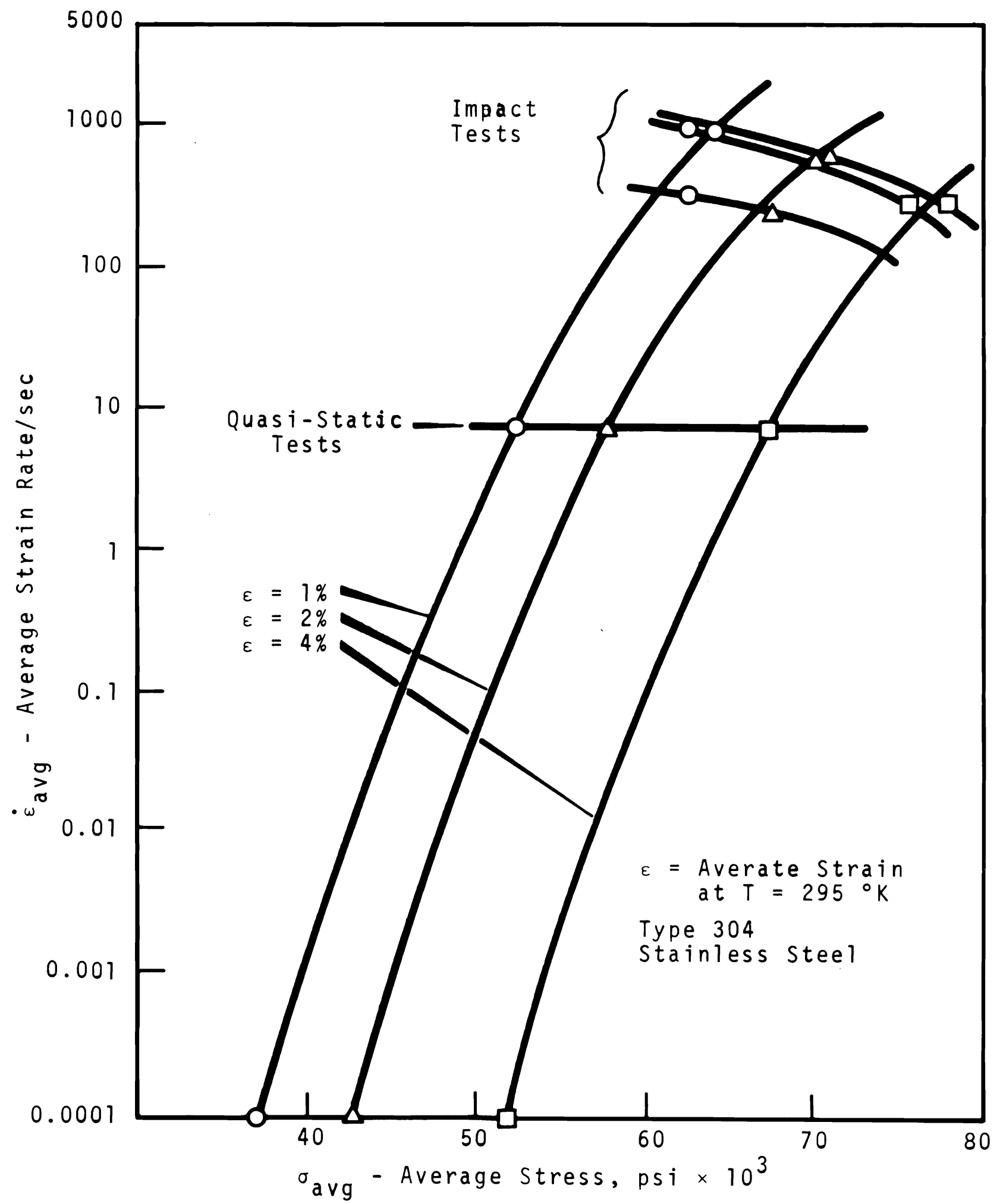

FIGURE 2. Effect of Stress on Strain Rate at Constant Strain

for stainless steel, Showing sampling of Experimental Record 
Hopkinson bar-bar impact machine, is described by Hauser in his paper. The Hopkinson technique, or the various modifications of it, is the most typical method of determining flow stress behavior in the strain rate range of $50 \mathrm{sec}^{-1}$ to $2000 \mathrm{sec}^{-1}$. No ductility information is directly available from this type of test as the specimens are loaded in compression.

Strain rate has also been found to indirectly affect the amount of martensite formed during straining in metastable austenitic stainless steel. Bressanelli and Moskowitz(3) found that, in Type $301 \mathrm{SS}$, an increase in the strain rate causes a reduction in the amount of martensite formed at any given strain level. They found this effect attributable to adiabatic heating during plastic straining. A reduction in martensite formation during straining was found to decrease ultimate strength and elongation. Increasing the alloy content increases the austenite stability as evidenced by a lowering of the $M_{d}$ temperature. Above the $M_{d}$ temperature, of course, this phenomenon is unimportant. Some earlier work by Form and Baldwin (4) was also intended to evaluate the significance of strain rate and temperature on martensite formation in Type 303 and 310 Ss. Their results, while not fully accounting for the observed behavior, are interpretable in terms of the explanation offered by Bressanelli and Moskowitz. The test results of Form and Baldwin, although presented only in terms of the natural logarithm of the ratio of original area to the final areas, are of interest here because of the wide range of temperatures and strain rates employed. The results for Type 303 SS and Type 310 SS are shown in Figures 3 and 4, respectively. In these figures, the strain rates are given in terms of $\mathrm{min}^{-1}$ and must be multiplied by $1.67 \times 10^{-2}$ convert to $\mathrm{sec}^{-1}$. Both types of steels show similar ductility behavior. At slow rates $\left(<10^{-1} \mathrm{sec}^{-1}\right)$, a maximum in ductility occurs at 
BNWL-1105

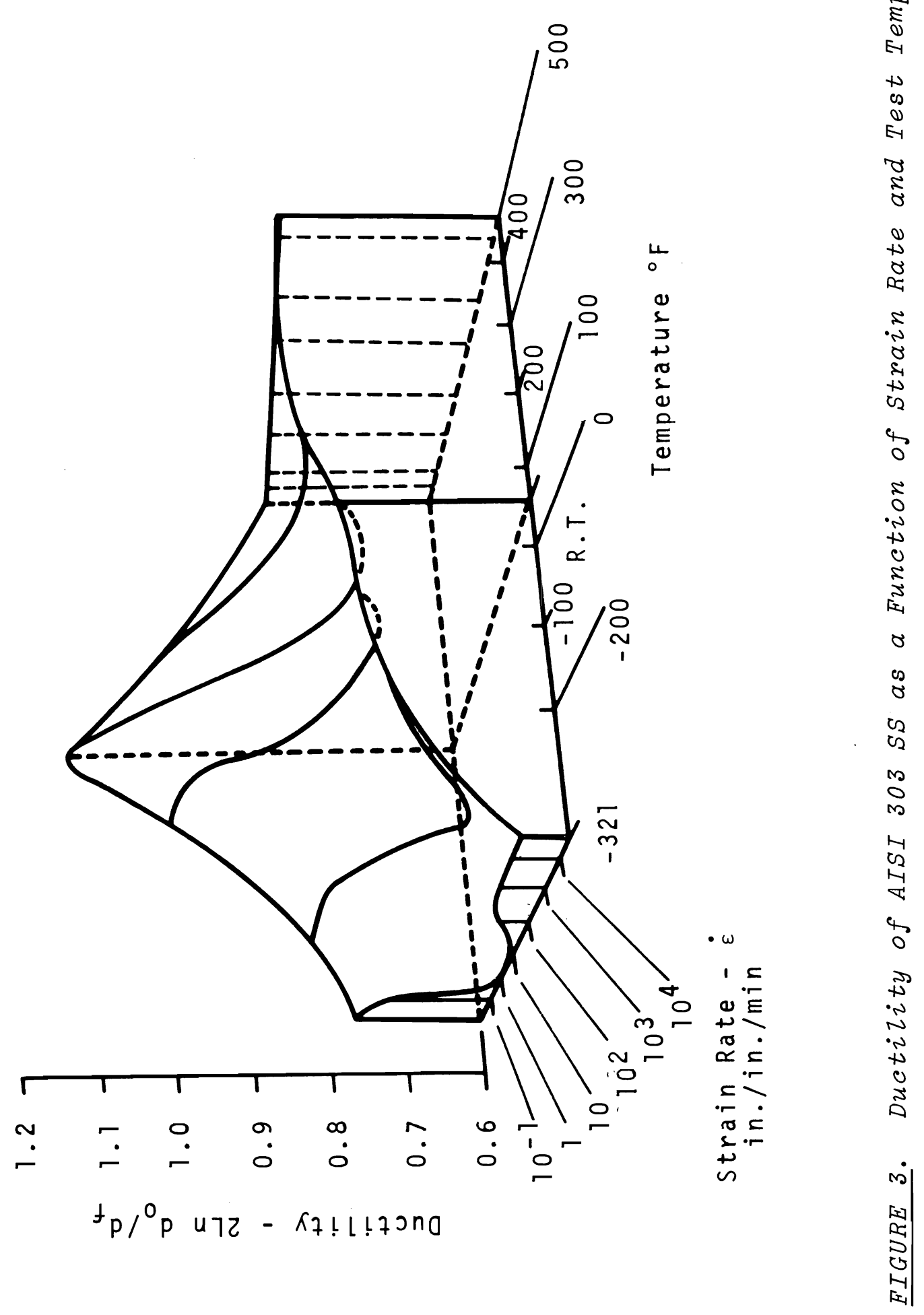


BNWL - 1105

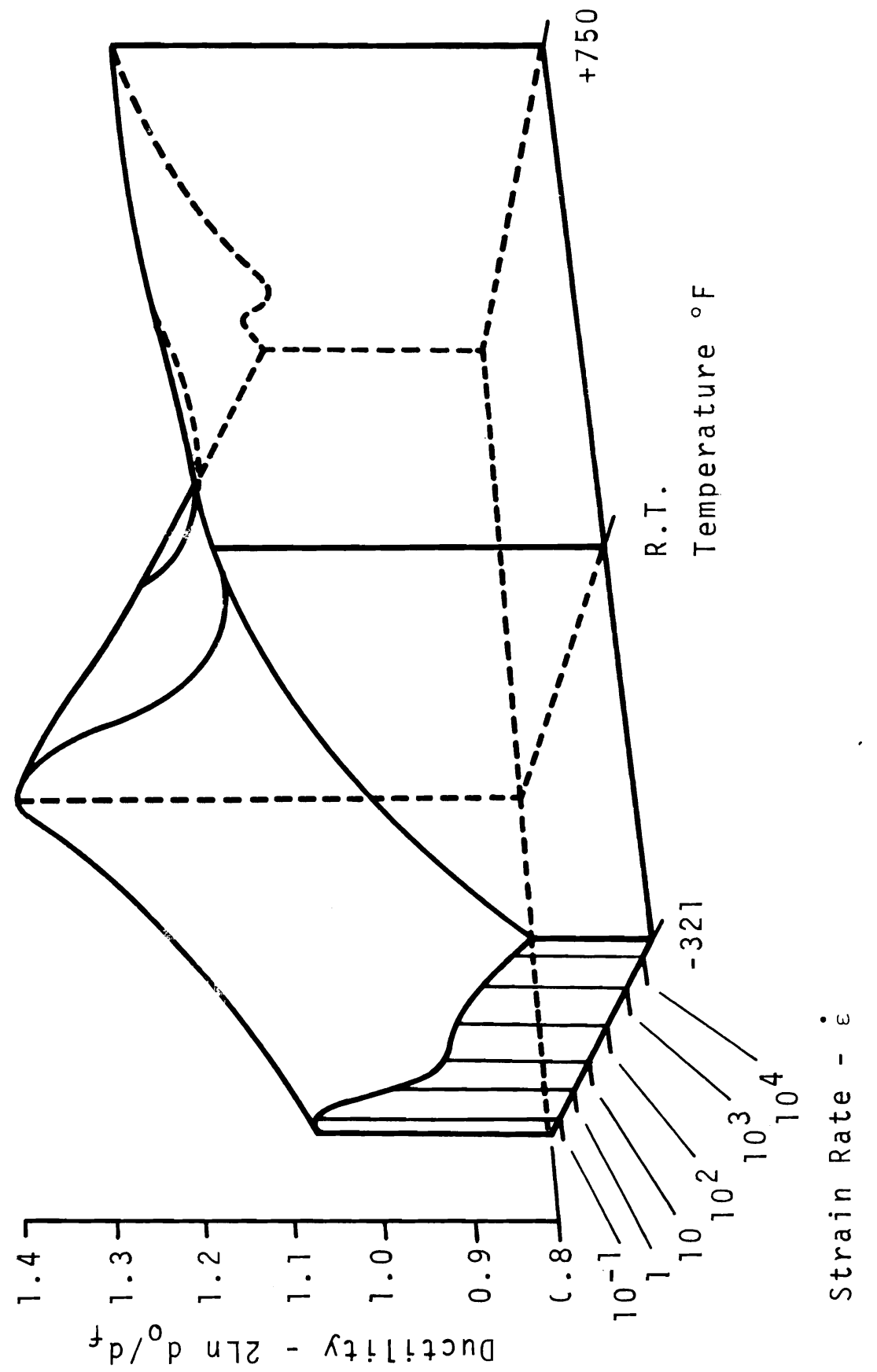

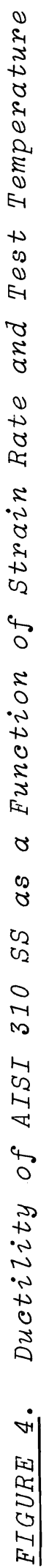


approximately room temperature, while at strain rates of about $20 \mathrm{sec}^{-1}\left(10^{3} \mathrm{~min}^{-1}\right)$ and above the ductility increases monotonically with increasing temperature.

Some additional test data on Type 301 SS at temperatures from $1600^{\circ} \mathrm{F}\left(870^{\circ} \mathrm{C}\right)$ to $2240^{\circ} \mathrm{F}\left(1230{ }^{\circ} \mathrm{C}\right)$ have been obtained by Roe and Kattus. (5) This work, shown in Figures 5 and 6 indicates a quite large rate sensitivity in the flow stress at these high temperatures. The ductility is also fairly strain rate sensitive and increases with increasing strain rate. This data contrasts the room temperature behavior where, for example, Moon and Campbe11 (6) show only a $15 \%$ increase in the ultimate strength of Type 301 SS for a change from static to rates of $1 \mathrm{sec}^{-1}$. In the case of Type $302 \mathrm{SS}$, Clark and Wood (7) found a $19 \%$ increase in ultimate tensile strength in going from static rates to approximately $100 \mathrm{sec}^{-1}$.

At strain rates of the order of $10^{3} \mathrm{sec}^{-1}$, Type $304 \mathrm{SS}$ has been found to become fairly rate sensitive even at room temperature, as has been demonstrated by Johnson et al. The fact that this material becomes more rate sensitive at high strain rates is also suggested by Hauser's data in Figure 2. A comparison of the static and dynamic stress-strain relation obtained by Johnson et a1. is shown in Figure 7 . The dynamic data were obtained from an exploding ring test in which the specimen material was machined into a ring and then pressed onto a cylindrical core. The cylindrical core had a high explosive packed into a hole along its axis. After detonation, the ring trapped a portion of the compressive shock wave emanating from the center of the core, and its progressive expansion was monitored by high speed photography. In their tests on the Type $304 \mathrm{SS}$, plastic strain rates of approximately $4.5 \times 10^{3}$ $\sec ^{-1}$ were obtained. This test technique appears to have an advantage of stressing the entire specimen uniformly. In the more conventional shock tests, a rod of the test material 


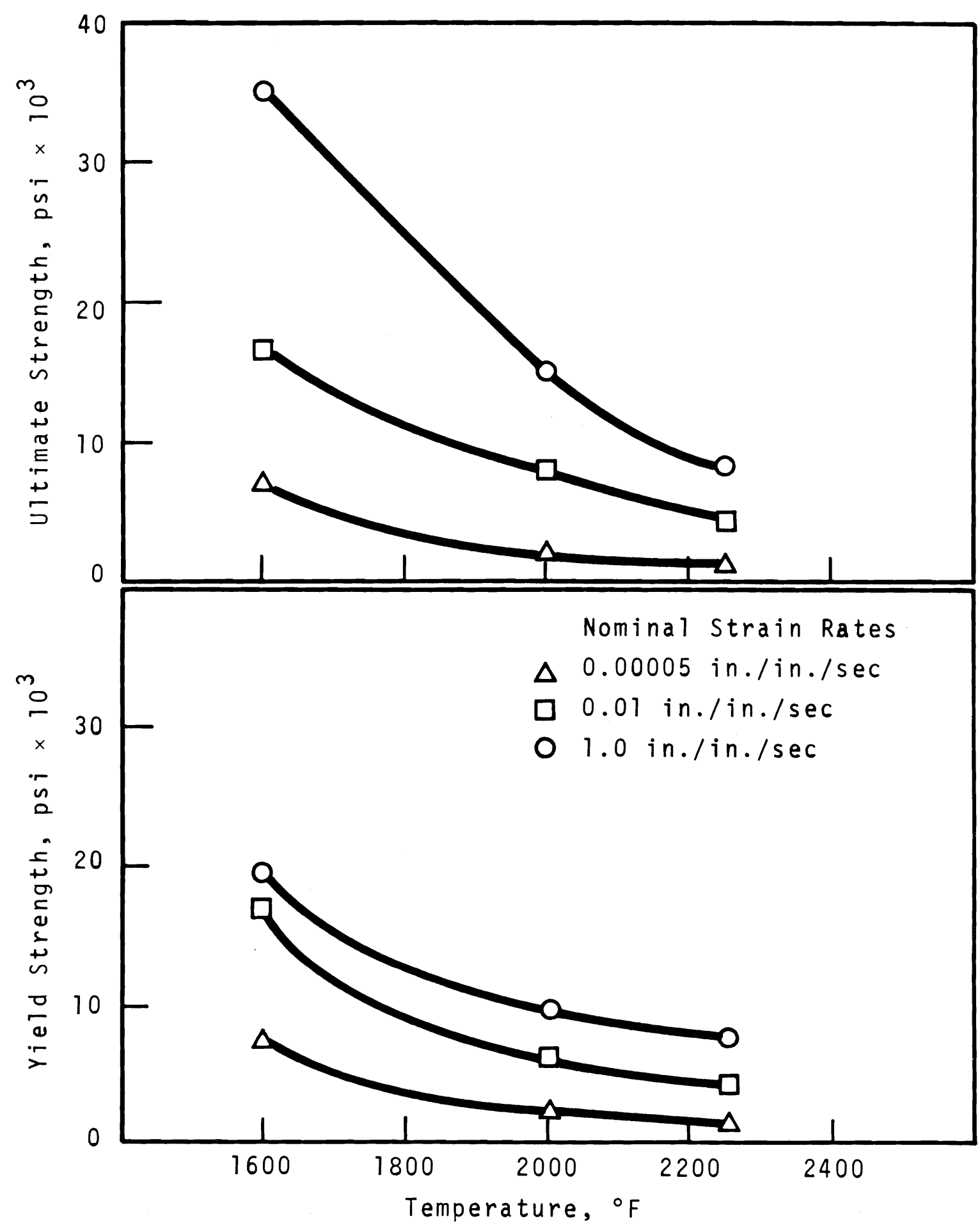

FIGURE 5. Temperature Effect After 1800-sec Hold Time on 0.2\% offset Yield and Ultimate Tensize Strength of FulZHard 301 SS sheet at Different Strain Rates (Specimens heated to test temperature in 10 sec) 


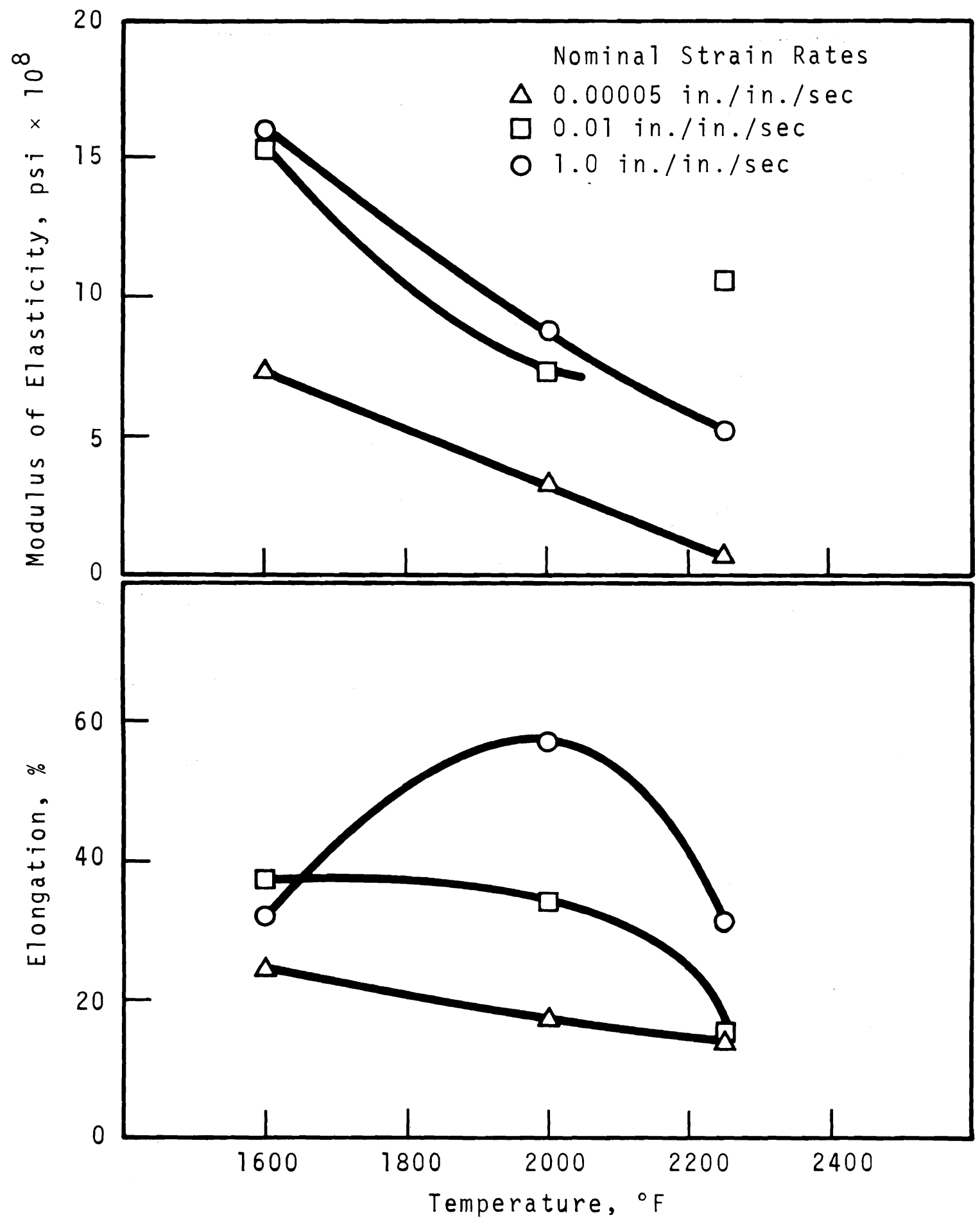

FIGURE 6. Temperature Effect After 1800-sec Hold Time on Percent Elongation and Modulus of Elasticity of FullHard 301 SS Sheet at Different Strain Rates

(Specimens heated to test temperatures within $10 \mathrm{sec}$ ) 
BNWL - 1105

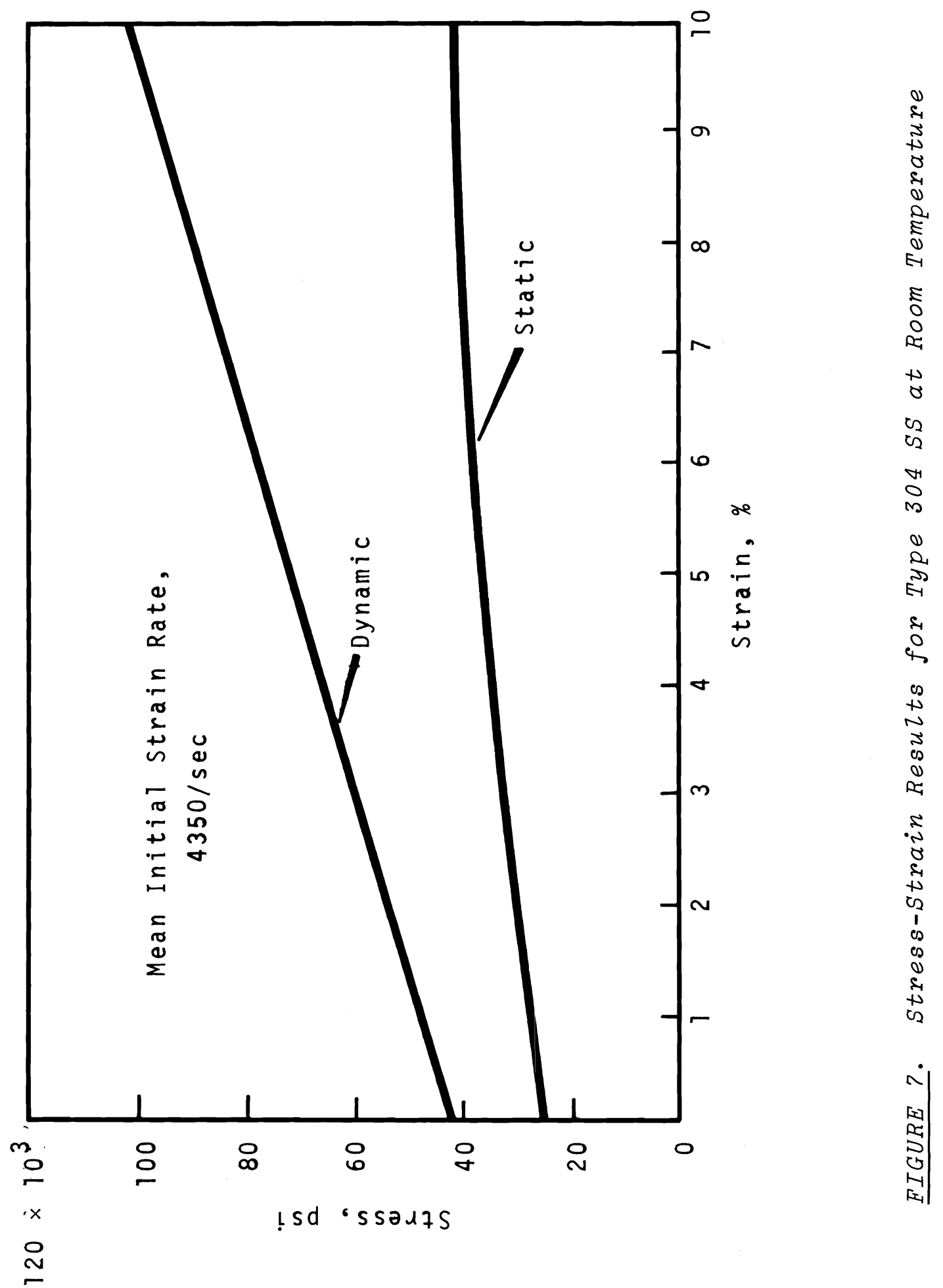


BNWL- 1105

shocked at one end stresses the material by means of a shock wave propagating down the length of the rod.

Test results on cold worked Type 304 SS at temperatures of $74^{\circ} \mathrm{F}\left(23^{\circ} \mathrm{C}\right)$ and $900^{\circ} \mathrm{F}\left(482^{\circ} \mathrm{C}\right)$ in the strain rate range of $10^{-5}$ to $10^{2} \mathrm{sec}^{-1}$ steel have been provided by Jackson. (9) These data, shown in Figures 8 and 9 , differ distinctly in several respects from the results described previously. First, the flow stress becomes less rate sensitive at higher strain rates. Secondly, in this temperature range, the rate sensitivity does not increase significantly (if at a11) with increasing temperature. Finally, total elongation decreases at $900^{\circ} \mathrm{F}$ with increasing strain rate as it does at room temperature. While this latter point differs from the results of Martin and Weir, and Form and Baldwin, the comparison may not be strictly valid because of differences in the method of measuring ductility. However, based on these limited results, cold working appears to alter the strain rate behavior of Type 304 SS significant1y.

\section{DEFORMATION BEHAVIOR UNDER DYNAMIC CONDITIONS}

The statement that a force suddenly applied to a body is not instantaneously transmitted to the remote portions of the body, while quite obvious, implies a mode of behavior which may be extremely complex. The disturbances produced by the force may separate into several components or waves, with each propagating through the body at different speeds depending on the elastic constants and the stress plastic strain relation. One of the more elementary problems of wave propagation in solids is the propagation of a longitudinal wave in a slender rod. This problem will be considered here not only for its simplicity but also because it demonstrates some of the behavior common to more complex geometries and loading conditions.

Consider first an infinitesimal element of volume in a rod shown in Figure 10. If we suppose the longitudinal stress 
BNWL - 1105

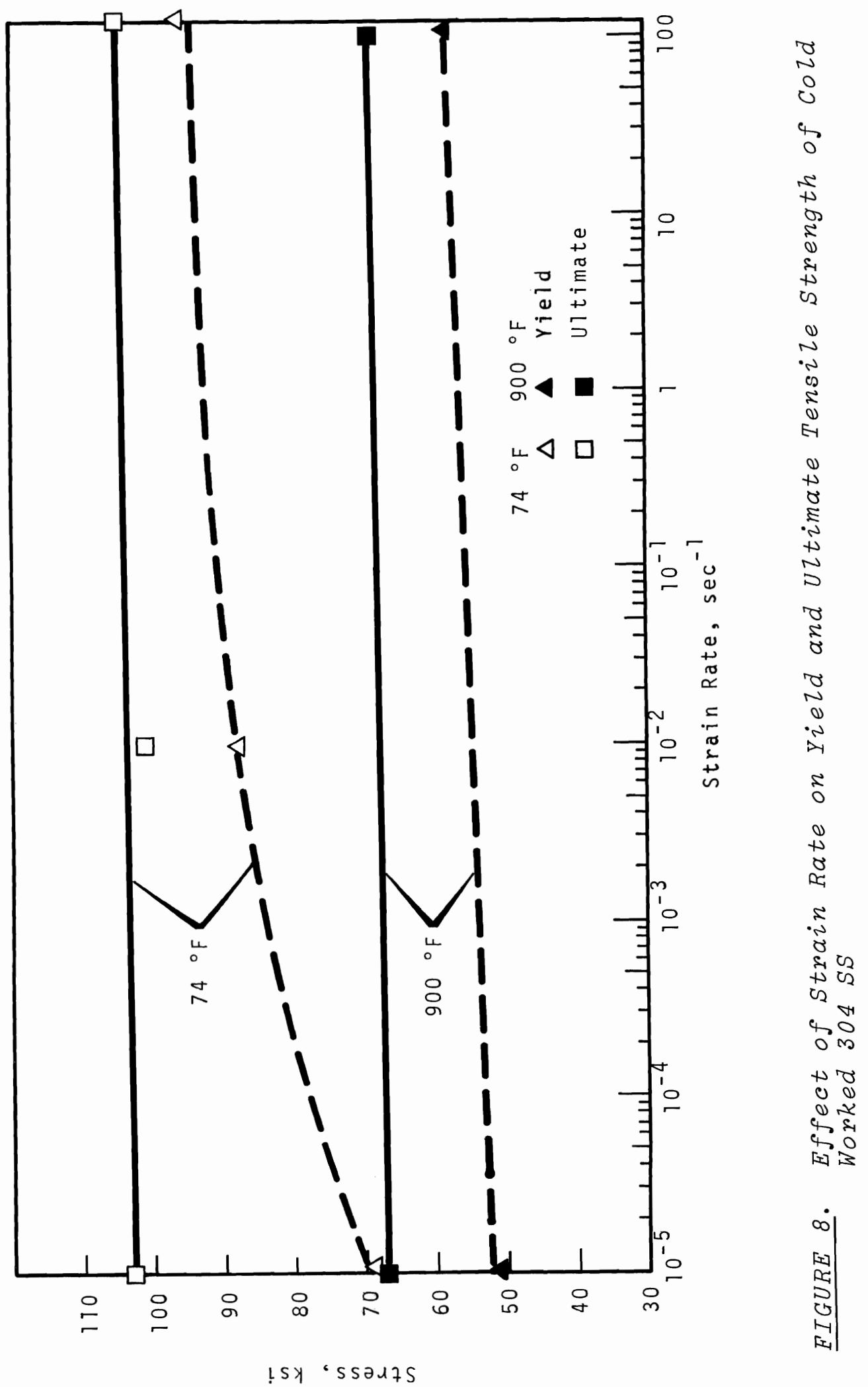


BNWL- 1105

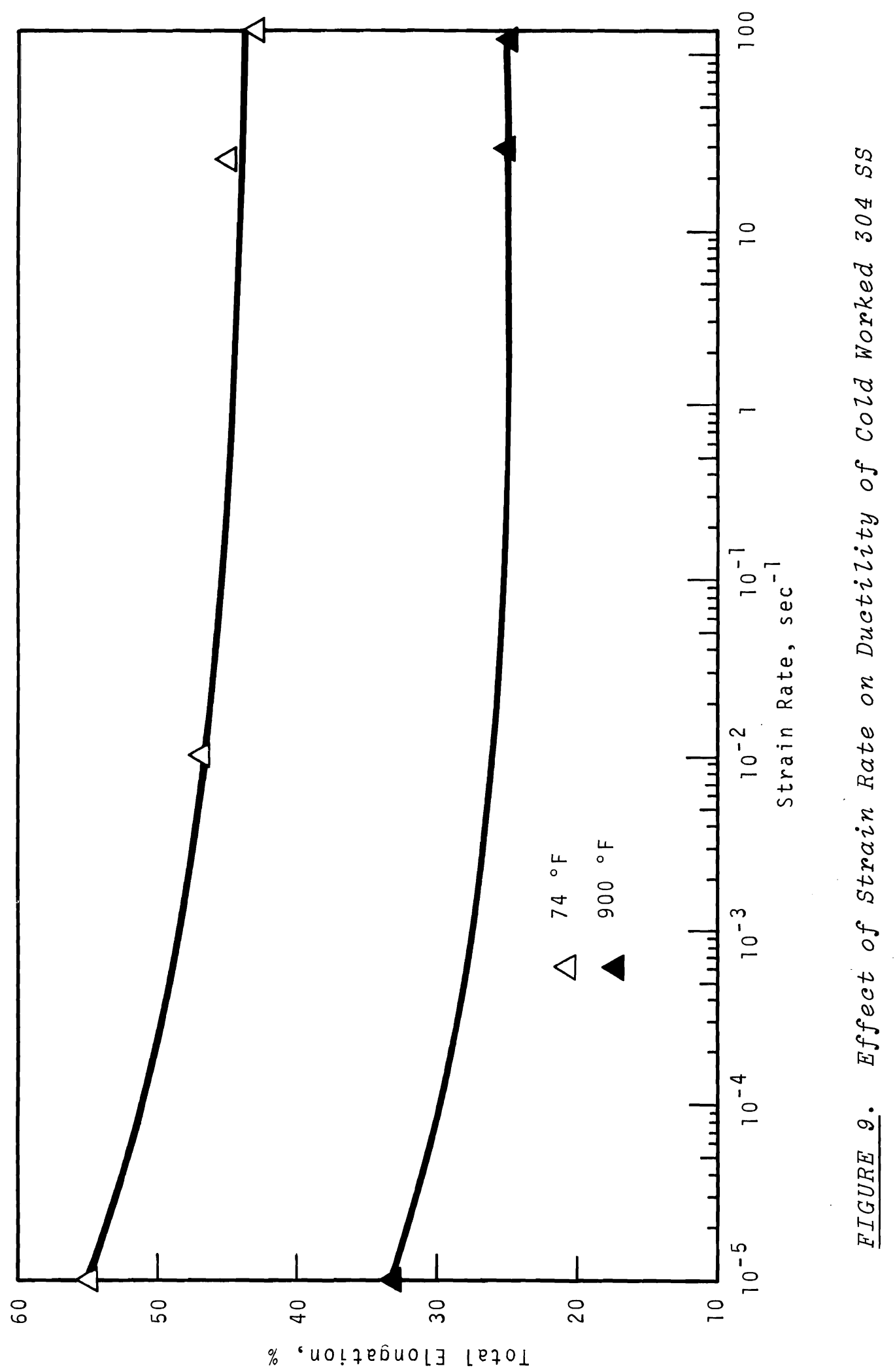




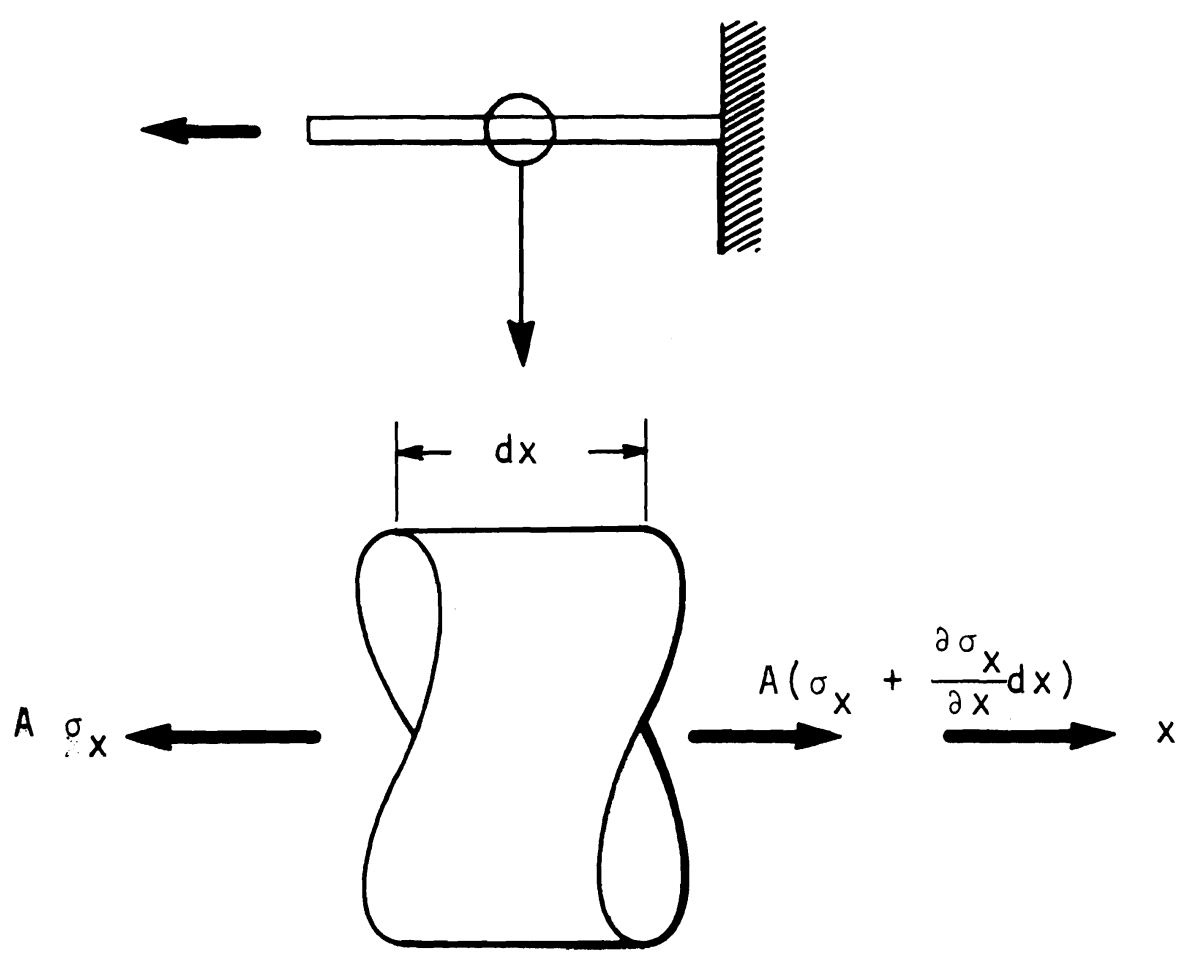

FIGURE 10. Schematic of Cylinderical Rod Subjected to Rapid EZongation

on one side to be slightly greater by an amount $\left(\partial \sigma_{x} / \partial x\right) d x$, then the net force on the element is simply $A\left(\partial \sigma_{x} / \partial x\right) d x$, where $A$ is the cross-sectional area. In time $t$, the element will displace a distance $u$ and we may write the net initial force on the element as

$$
\operatorname{dm} \frac{\partial^{2} u}{\partial t^{2}}=A \frac{\partial \sigma}{\partial x} d x
$$

where $\mathrm{dm}$ is mass of the element and is given by $\rho \mathrm{Adx}$ $(\rho=$ density). Substituting for dm, Equation (1) becomes,

$$
\rho \frac{\partial^{2} u}{\partial t^{2}}=\frac{\partial \sigma x}{\partial x}
$$

If the deformation is purely elastic,

$$
\sigma_{x}=E e_{x}=E \frac{\partial u}{\partial x}
$$

Eliminating $\sigma_{x}$ from Equation (2) gives the wave equation 


$$
\frac{\delta^{2} u}{\delta t^{2}}=\frac{E}{\rho} \frac{\delta^{2} u}{\delta x^{2}}
$$

The solution to this equation represents a wave propagation along the $x$-axis with speed, $c_{0}$, equal to $\sqrt{E / \rho}$. Armed with this information, we may now consider the situation in which a rod is rigidly fixed at one end and the other end suddenly acquires a constant velocity, $v$. To further simplify this example, we will assume that the material has a constant rate of strain hardening, $\theta=\mathrm{d} \sigma / \mathrm{d} \varepsilon_{\rho}$, beyond yield point. This latter assumption provides a constant propagation velocity to the plastic portion of the wave since, from the von Karman (10) theory, the plastic wave velocity is given by

$$
C_{p}=\sqrt{(1 / \rho)\left(\mathrm{d} \sigma / \mathrm{d} \varepsilon_{\rho}\right)}=\sqrt{\Theta / P} \quad .
$$

Now, the sudden increase in velocity of the free end produces a stress at the end, and it may be shown from the impulse-momentum principle that this stress is

$$
\sigma=\rho \mathrm{C} \Delta \mathrm{v}
$$

with $\Delta v$ the velocity change in any element of volume. This is known as the particle velocity. In the case of Type $304 \mathrm{SS}$ where $E=28 \times 10^{6} \mathrm{psi}$ and $\mathrm{C}_{0}=2 \times 10^{5} \mathrm{ips}$, the $\mathrm{v}$ required to attain a stress of 30,000 psi (approximate yield strength) is about 16 fps (192 ips). First, examine the case whore $r$ is such that $\sigma=\sigma_{y} / 2$. Then a purely elastic wave propagating towards the fixed end will be generated. The stresses ahead of the wave are zero and the material is at rest. Behind the wave, the stress is $\sigma_{y} / 2$ and the particle velocity is $v=\sigma_{y} / 2 \rho C_{0}$. After time $t=L / C_{0}$, where $L=b a r$ length, the wave reaches the fixed end. Since the bar is rigidly mounted, the particle velocity must be zero at the fixed end and, the fore, the particle velocity behind the wave must change to zero when the wave reaches this location. This condition is 
satisfied by the superposition of a second wave whose propagation and particle velocity are of equal magnitude but in the opposite direction. Adding this wave to the original wave yields a wave propagating back toward the face end with speed $\mathrm{C}_{0}$, amplitude $\sigma_{y}$, and a net particle velocity of zero behind it. Upon reaching the free end, another wave is superimposed due to the constant velocity of the free end. However, the increased stress associated with this third wave results in a total stress in the plastic range, and so the stress increment is smaller and is expressed by $\Delta \sigma=v_{p} C_{p}$, giving a total stress of $\sigma_{y}+\Delta \sigma$. This plastic wave continues the process except at a slower rate. The stress is increased at each end until fracture occurs. It is interesting to note that fracture will always occur at one of the ends if the bar is homogeneous.

If the velocity of the free end is greater than that required to initiate yielding, then a different distribution of plastic strains is likely. For example, consider the case in which $v>\sigma_{y} / \rho C_{0} \cdot$ Both a plastic and an elastic wave are generated. The magnitude of the elastic wave is $\sigma_{y}$, and the magnitude of the plastic wave can be obtained from the displacement at the free end. This displacement is composed of an elastic and a plastic term

$$
v t=\delta_{e}+\delta_{p} .
$$

In time $t$, the elastic wave has travelled $C_{0} t$ down the bar and the plastic wave has travelled $\mathrm{C}_{\mathrm{p}} t$ so the average elastic strain $=e=\delta e_{e} / C_{0} T=\sigma_{x} / E$ and the average plastic strain $=E_{p}=\delta_{p} / C_{p} t=\left(\sigma-\sigma_{x}\right) / \theta$. Substituting into Equation (4) and solving for the plastic stress increment gives

$$
\sigma-\sigma_{y}=\frac{\ominus}{C_{p}} V-\frac{\delta_{y} C_{o}}{E} \text {. }
$$


This plastic wave propagates more slowly than the elastic wave $\left(\mathrm{C}_{\mathrm{o}}>\mathrm{C}_{\mathrm{p}}\right)$ and the particle velocity associated with it is a fraction of the total velocity of the end of the bar. The remaining portion of the total velocity is associated with the elastic wave which, in this case, is $\sigma_{y} / \rho_{0} C_{0}$. The fact that the particle velocity of the elastic wave must go to zero upon reaching the fixed end means that the stress at the fixed end will be increased by an amount of $C_{p} \sigma_{y} / C_{o}$. If this additional stress causes fracture, an elastic wave unloading the bar will return from the broken end. This unloading wave will reach the plastic wave after it has progressed a distance of $2 \mathrm{C}_{\mathrm{p}} \mathrm{L} / \mathrm{C}_{\mathrm{p}}+\mathrm{C}_{\mathrm{o}}$. It is $1 \mathrm{ikely}$, then, that the stresses associated with the plastic wave will be reduced below $\sigma_{y}$. The net result in this imaginary experiment is that of a bar plastically deformed over only a fraction of its length but whose fracture strength is exceeded.

If we were to consider the more realistic case where $\theta=\theta\left(\varepsilon_{p}\right)$ and $\sigma=\sigma(\dot{\varepsilon})$, the analysis would become considerably more difficult. The problem, in fact, could not be solved in closed form even for a simple geometry as a slender rod. For complex geometries composed of strain rate sensitive materials, a realistic incorporation of materials data into an analysis of the high velocity mechanical behavior of the structure would require a rather difficult and complex numerical calculation and/or an experimental evaluation of sub-scale model behavior. 


\section{$\underline{\text { REFERENCES }}$}

1. W. R. Martin and J. R. Weir. "The Effect of Irradiation Temperature on the Post-Irradiation Stress-Strain Behavior of Stainless Steel," Am. Soc. Testing Mater., Spec. Tech. Publ., vol. 380, p. 251. 1965.

2. F. E. Hauser. "Techniques for Measuring Stress-Strain Relations at High Strain Rates," Exp. Mech., p. 395. August 1966.

3. J. P. BressanelZi and A. Moskowitz. "Effects of Strain Rate, Temperature, and Composition of Tensile Properties of Metastable Austenitic Stainless Steels," Trans. Am. Soc. Metals, vol. 59, p. 223.1966.

4. G. W. Form and W. M. Baldwin, Jr. "The Influence of Strain Rate and Temperature on the Ductility of Austenitic stainless Steel," Trans. Am. Soc. Metals, vol. 48, p. 474. 1956.

5. W. P. Roe and J. R. Kattus. Tensile Properties of AircraftStructural Metals at Various Rates of Loading After Rapid Heating, WADC-TR-55-199. Wright Patterson AFT, Ohio, 1957.

6. Moon and Campbezl. Effect of Moderately High Strain Rates on the Tensize Properties of Metals, DMIC-Memo-142. Battelle Memorial Institute, Columbus, Ohio, 1961

7. Clark and Wood. "Tensize Impact Properties of Some Metals and Alzoys," Proceedings of the Western Metals Congress, Los Angeles, California, 1949.

8. P. C. Johnson, B. A. Stein, and K. S. Davis. "Measurement of Plastic Flow Properties Under Uniform Stress," Am. Soc. Testing Mater., Spec. Tech. Publ., vol. 336 , p. 195. 1963 .

9. R. J. Jackson. Unpublished Data. Battelle-Northwest, Richland, Washington, 1969. (Unpublished Results)

10. T. von Karman and P. Duwez. J.Appl. Phys., vol. 21, p. 987. 1950 . 


\section{DISTRIBUTION}

OFFSITE

AEC Chicago Patent Group

31 AEC Division of Reactor Development and Technology M. Shaw, Director, RDT Asst Dir for Nuclear Safety Analysis \& Evaluation Br, RDT:NS Environmental \& Sanitary Engrg Br, RDT:NS Research \& Development Br, RDT:NS Asst Dir for Plant Engrg, RDT

Facilities $\mathrm{Br}$, RDT:PE Components $\mathrm{Br}, \mathrm{RDT}: \mathrm{PE}$ Instrumentation \& Control $\mathrm{Br}, \mathrm{RDT}: \mathrm{PE}$ Liquid Metal Systems Br, RDT:PE Asst Dir for Program Analysis, RDT Asst Dir for Project Mgmt, RDT Liquid Metals Projects Br, RDT:PM FFTF Project Manager, RDT:PM (3) Asst Dir for Reactor Engrg, RDT Control Mechanisms Br, RDT:RE Core Design Br, RDT:RE (2)

Fuel Engineering $\mathrm{Br}, \mathrm{RDT}: \mathrm{RE}$

Fue 1 Handling $\mathrm{Br}$, RDT: RE Reactor Vesse1s Br, RDT:RE Asst Dir for Reactor Tech, RDT Coolant Chemistry Br, RDT:RT Fuel Recycle Br, RDT:RT Fuels \& Materials Br, RDT:RT Reactor Physics Br, RDT:RE Special Technology Br, RDT:RT Asst Dir for Engrg Standards, RDT EBR-II Project Manager, RDT:PM

1 AEC Idaho Operations Office Nuclear Technology Division

C. W. Bills, Director

1 AEC San Francisco Operations Office Director, Reactor Division

$4 \quad$ AEC Site Representatives Argonne National Laboratory Atomics International Atomic Power Development Assoc. General Electric Co. 
No. of

Copies

214 AEC Division of Technical Information Extension

3 Argonne National Laboratory

R. A. Jaross

LMFBR Program Office

N. J. Swanson

1 Atomic Power Development Assoc. Document Librarian

$7 \quad$ Atomics International FFTF Program Office

Liquid Metal Information Center J. J. Droher (2)

2 Babcock \& Wilcox Co.

Atomic Energy Division

S. H. Esleeck

G. B. Garton

$1 \quad$ BNW Representative

N.A. Hill (ZPR III)

1 Combustion Engineering

1000 MWe Follow-On Study

W. P. Staker, Project Manager

$5 \quad$ General Electric Company

Advanced Products Operation

Karl Cohen (4)

Nuclear Systems Programs

D. H. Ahmann

2 Gulf General Atomic Inc. General Atomic Div

D. Coburn

1 Idaho Nuclear Corporation

D. R. deBoisblanc 
No. of

Copies

1 Oak Ridge National Laboratory

W. O. Harms

1 Stanford University

Nuclear Division

Division of Mechanical Engrg

R. Sher

1 United Nuclear Corporation

Research and Engineering Center

R. F. DeAngelis

5 Bechte1 Corporation*

J. J. Teachnor, Project Administrator, FFTF

10 Westinghouse Electric Corporation*

Atomic Power Division

Advanced Reactor Systems

J. C. R. Ke11y

ONSITE-HANFORD

1 Bechtel Corporation*

M. 0. Rothwe11 (Richland)

1 Westinghouse Electric Corporation*

R. Strzelecki (Richland)

4 AEC RDT Site Representative

P. G. Holsted

T. A. Nemzek

3 AEC Richland Operations Office

J. M. Shivley

1 AEC Chicago Patent Group

R. K. Sharp (Richland)

3 Batte11e Memorial Institute

* Distribution by FFTF 
No. of

Copies

$57 \quad$ Battelle-Northwest
E. R. Astley
A. L. Bement
D. C. Boyd
T. T. Claudson
J. C. Cochran
D. L. Condotta
J. F. Erben
E. A. Evans
L. M. Finch
F. C. Gronemeyer
B. R. Hayward
R. G. Hoagland (10)
P. L. Hofmann
J. E. Irvin
M. Jakub
R. N. Johnson
M. D. Jones
H. E. Little
W. B. McDonald
J. S. McMahon
R. Moen
R. J. Squires
J. M. Steichen
D. D. Stepnewski
J. C. Tobin
J. C. Tverberg
Legal - $703 \mathrm{~B} 1 \mathrm{dg}$.
Lega1 - ROB, 221-A
BNW - Technical Information (5)
BNW - Technical Publications (2)
FFTF File (703) (10)
FFTF TPO (703) (3) [ List "T"] 